\title{
Anterior Uveitis
}

National Cancer Institute

\section{Source}

National Cancer Institute. Anterior Uveitis. NCI Thesaurus. Code C35109.

Inflammation of the iris and anterior chamber of the eye. 